\title{
Digital Image Processing Of Friction Stir Weld Bead Surface Using Profiling and Contouring For Weld Quality Assessment
}

\author{
R.Rajashekar ${ }^{1}$, B.M.Rajaprakash ${ }^{2}$ \\ I(Asst. Professor, Mechanical Engineering Department, UVCE, Bangalore, India) \\ ${ }_{2}^{2}$ (Professor, Mechanical Engineering Department, UVCE, Bangalore, India)
}

\begin{abstract}
The shoulder of friction stir welding tool influences properties of welded or processed zone from appearance to internal microstructural features. The main function of the tool shoulder is the control of work piece material towards the probe by rotational flow generated by the tool and the force distribution under the shoulder generating required temperature and hydrostatic pressure to ensure proper containment and consolidation in forming defect free weld. The efficiency of the shoulder in this regard may be evaluated by the surface appearance and uniformity of the weld bead. In the present study, the images of weld bead surface of friction stir welded specimens produced using different process parameters is analyzed using image processing technique. The images are digitally processed and analyzed by defining suitable region of interest along good and defect weld region based on X-Ray radiography results of friction stir welded specimens. The line profile plot along the weld line and contour plot of weld bead images are plotted using MATLAB. The variation in the slope of line profile plot and appearance in the contour plot along good and defect weld regions are observed which enables to assess the quality of weld using image processing.

Keywords -Contouring, Digital image processing, Friction stir welding, Profiling, X-Ray radiography
\end{abstract}

\section{INTRODUCTION}

Friction stir welding (FSW), a solid-state joining technique developed by The Welding Institute (TWI) in 1990s. It has been a prominent process in welding similar and dissimilar aluminum alloys in which joining of material is achieved without melting. As such, FSW has many advantages over traditional fusion welding and has been used in wide variety of applications in the automotive, aerospace, ship building, and railroad industries $[1,2]$. A schematic representation of the FSW process as applied to a butt joint of two flat plates is shown in Fig.1. FSW involves a special rotating cylindrical tool which consists of a shoulder and a small diameter probe connected to it. The tool shoulder, with larger diameter than that of the probe, prevents the material from being expelled from the workpiece to be welded which minimizes the formation of voids in the welded area. Once the plates are butted on a common axis, placed on a backup plate and clamped rigidly to prevent lateral movement, the rotating tool is plunged into the welding workpiece until the shoulder is brought into close contact with the surface of the two parts to be joined. The main part of process heat input is induced by friction between tool shoulder and plates. Once the probe is inserted, it moves in the welding direction. As the tool moves along the joint line, the heated and plasticized material is essentially extruded around the tool before being forged by the shoulder where it consolidates and forms the weld. The tool axis tilted by $2^{\circ}$ or $3^{\circ}$ from the vertical facilitate consolidation of the material resulting in a high quality solid-state weld [3, 4].

Dwight A. Burford et al. [5] examined the welds produced by FSW process using aluminum alloys by tools with various shoulders. They confirmed that the surface roughness and metal deformation in the uppermost layers of welds are greatly influenced by shoulder design. The shoulder of friction stir welding and tools directly and indirectly influences many properties in a welded or processed zone, from appearance to internal microstructural features. Among the key functions of the tool shoulder, it is the control of material flow to ensure proper containment and consolidation. The efficiency of the shoulder in this regard may be evaluated by the amount of flash that is produced along with surface appearance and uniformity of the weld track. The shoulder contribution to material flow depends upon how well the shoulder directs work piece material towards the pin for a given tool tilt angle. A shoulder with a sufficient inwardly directed traction force is needed to contain the work piece material producing the defect free weld.

Muthukumaran and Mukherjee [6] established experimentally the multilayered metal flow phenomenon in FSW which is due to stick and slip conditions caused by the variation in the contact pressure of tool with workpiece. The pin and shoulder transform the metal layer by layer along the retreating side contributing to the first and second modes of metal transfer respectively. The metal transferred by the shoulder offers compressive force on the metal transferred by the pin which merges together with adequate temperature and hydrostatic pressure generated from the shoulder contact with the base material. Kumar and Kailas $[7,8]$ analyze the material flow during friction stir weld formation and found that When shoulder contact is increased the axial load increases transferring the increased amount of flow of material from the leading edge into weld cavity. 
This prevents the material from flowing out of the weld cavity producing sufficient amount of friction heat and hydrostatic pressure, which attributes compactness to the weld leading to elimination of weld defects normally caused by inadequate compactness.

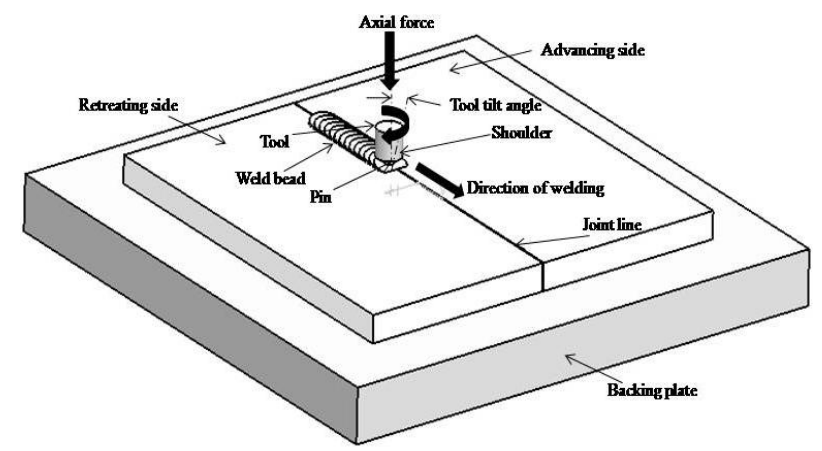

Fig.1 Schematic diagram of friction-stir welding process and terminology

A J Leonard and S A Lockyer [9] described the causes for number of flaws encountered in FSW by characterizing the welds using X-ray and ultrasonic non-destructive testing techniques. A void is a flaw encountered along the advancing side between the weld nugget and the reminder of thermomechanically affected zone and small voids were also observed below the top of the weld. The main cause for the voids is incomplete consolidation due to insufficient forging pressure applied to the tool. The tool shoulder for a given tool tilt angle plays an important part in forging the material that has been plasticized by the rotating pin in the joint line. When welding at higher travel speeds, the material receives less work per unit of weld length. Under such conditions, the plasticized material may be cooler, and less easily forged by the shoulder, resulting in voids remaining unconsolidated. From the above discussion it is clear that the proper interaction of shoulder with the base material is important and necessary to produce good weld. The interaction of the tool shoulder produces arc-shaped bands on weld surface, since the material is transferred by the sliding action of tool shoulder over the pin-driven material. A combined experimental and numerical investigation of FSW bead surface carried out by Shaowen XU and Xiaomin Deng [10] describes that the banded texture of weld has close ties to the microstructure of the weld region and that the bands have a strong effect on the mechanical behavior of the welded joints.

S.Muthukumaran et al.[11] discussed the image processing techniques to study the changes in the first mode of metal transfer during FSW to develop a methodology for online condition monitoring of FSW. The digital images of weld bead are processed and analyzed to study the variation in quality of weld subjected to pin failure and variable pin depth to detect any defects or abrupt changes in weld bead surface by profiling, contouring and histogram plot. With growing demand of industrial automation in manufacturing application of machine vision and image processing plays an important role in quality inspection and process monitoring of FSW. However they have not referred the results of any NDT like X-ray radiography for the occurrence of defect and quantification of image data determined from profile plot is not done for generating information in more realistic way for decision making using image processing techniques.

In this paper an attempt has been made to adopt digital image processing techniques to analyze the images of weld bead surface of friction stir weld. The variation in image parameters are studied from profile plot and contour plot of weld bead images, which are obtained by defining region of interest(ROI) along good and defect weld region based on X-Ray radiography results of friction stir welded specimens using MATLAB to assess the quality of the welds.

\section{experimental work}

The experiments are carried out producing friction stir welded specimens using base material of aluminium 7020-T6, a medium strength precipitation hard enable Al-Zn-Mg alloy used in aerospace industry for structural applications. The dimensions of base material used for production of weld is $300 \mathrm{~mm} \mathrm{x} 150 \mathrm{~mm} \mathrm{x}$ $5 \mathrm{~mm}$. The OHNS die steel tool is used with $4.6 \mathrm{~mm}$ long conical shaped pin of $6 \mathrm{~mm}$ top diameter and $4 \mathrm{~mm}$ bottom diameter with $25 \mathrm{~mm}$ flat shoulder diameter. The variable tool rotation speed and tool traverse speed (TABLE 1) are considered for producing specimens on modified milling machine with butt welded configuration and $2^{0}$ tool tilt angle. The images of specimens are captured for further analysis. 
Table1 Friction Stir Welding Parameters

\begin{tabular}{|c|c|c|c|}
\hline $\begin{array}{c}\text { Specimen } \\
\text { No. }\end{array}$ & $\begin{array}{c}\text { Tool rotation } \\
\text { speed } \\
(\mathbf{r p m})\end{array}$ & $\begin{array}{c}\text { Tool traverse } \\
\text { speed } \\
(\mathbf{m m} / \mathbf{m i n})\end{array}$ & $\begin{array}{c}\text { Weld distance } \\
(\mathbf{m m})\end{array}$ \\
\hline 1 & 1200 & 45 & 185 \\
\hline 2 & 1000 & 35 & 185 \\
\hline
\end{tabular}

\section{Methodology For Image Processeing}

The digital images of the welded specimens captured are processed to improve the image quality for analysis using image processing toolbox of MATLAB. In order to reduce the image data, the color image is converted to gray scale image and original image is cropped along weld bead. Filters are applied on weld bead images to reduce the noise. Further, images are enhanced by contrast stretching to improve the clarity of weld bead by "Contrast Limited Adaptive Histogram Equalization" operation.

From X-Ray radiography of the FSW specimens the defect regions on the weld bead are indentified. The rectangular area is defined along defect weld region and good weld region on processed weld bead images as region of interest (ROI). The profile plot of the images which shows the variation in gray intensity along the weld line is plotted. The linear fit of profile plot is made in order to quantify the image parameters by finding the slope of linear fit. The contouring of weld bead images is performed to display contour plot. A contour is a path in an image along which the image intensity values are constant. The variations in contour plot and slope of line profile plot along the good weld region and defect weld region are studied. The flowchart of image processing methodology is shown in Fig.2.

\section{Results and discussions}

The image processing techniques discussed in the methodology are adopted for the welded specimens produced as per TABLE1. The gray scale image of FSW specimen1 is shown in Fig.3. The weld bead image of specimen 1 is processed by histogram equalization to improve the contrast (Fig.4). Based on the X-Ray radiography of specimen1 (Fig.5) a suitable size of ROI is considered on weld bead to get the images of good weld region (Fig.6) and defect weld region(Fig.7).

Profiling of gray scale image gives pixel-value cross-sections along line segments. It computes the intensity values along a line or a multiline path in an image, selecting equally spaced points along the path specified and then uses interpolation to find the intensity value for each point. If the specified path consists of a single line segment, a two-dimensional plot of intensity values versus the distance along the line segment will be plotted. Profile plot of weld bead images along good weld region (Fig.8) and defect weld region(Fig.9) of specimen 1 is plotted along the weld line since, rotational flows of plasticized material take place in the vicinity of the tool, dragging the bulk of the stirred material to a final position behind the travelling tool and material deposition takes place layer-by-layer resulting in the formation of nugget zone . Also, consolidation of the transfer material takes place about the joint line filling the void of pin by the forging action of the shoulder due to tool tilt along a vertical plane passing through the joint line. Line profile plots of images of good weld region shows less variation in gray intensity values along weld line than defect weld region. These variations are due to the fact that the reflectivity of light is directly dependent on the nature of surface; smooth and even surface reflects more light than rough and wavy surface and such surfaces are produced due to the prevailing shoulder interaction with base material during welding. Further, variations in image data is quantified by finding the slope of linear fit of profile plot (TABLE 2). The Fig.10 clearly shows that the slope of good weld region are smaller than that of defect weld region indicating less variation in gray intensity values. 


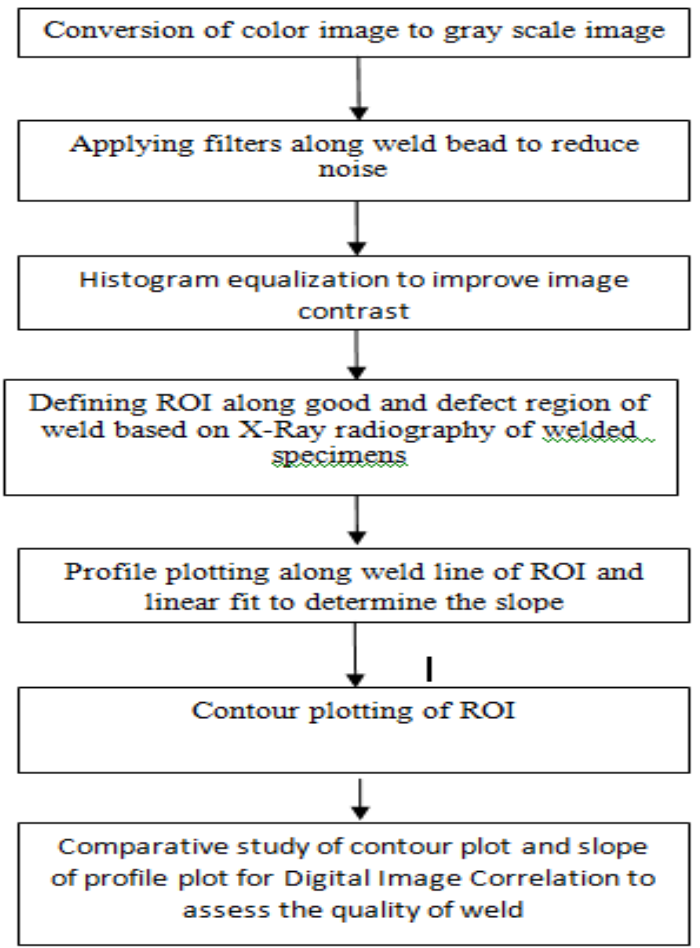

Fig.2 Image Processing Methodology

Contouring of grayscale image automatically sets up the image axes so that their orientation and aspect ratio match size of the image. The number of equally spaced contour levels are plotted, where a contour is a path in an image along which the image intensity values are constant. The contour plot of images of good weld region (Fig.11) and defect weld region (Fig.12) of specimen1 are plotted. The contour plot of good weld region shows consistency in the contouring data. The contour lines are continuous and uniform along weld zone which indicates proper interaction of shoulder during weld formation. The contour plot of defect weld region shows broken and discontinuous contour along weld zone indicating improper interaction of shoulder leading to defect in the weld.

The similar trend of variation in slope of line profile plot and contour plot has been observed for specimen 2 welded with different process parameters. Fig. 13 shows gray level image of FSW specimen 2 which is processed by image processing technique to improve the quality and cropped along weld bead (Fig.14). Based on the X-Ray radiography (Fig.15) the weld bead image is further cropped by defining ROI of suitable size along defect weld region (Fig.16) and good weld region (Fig.17). Profile plot of weld bead images along good weld region (Fig.18) and defect weld region (Fig.19) of specimen 2 is plotted along the weld line. Line

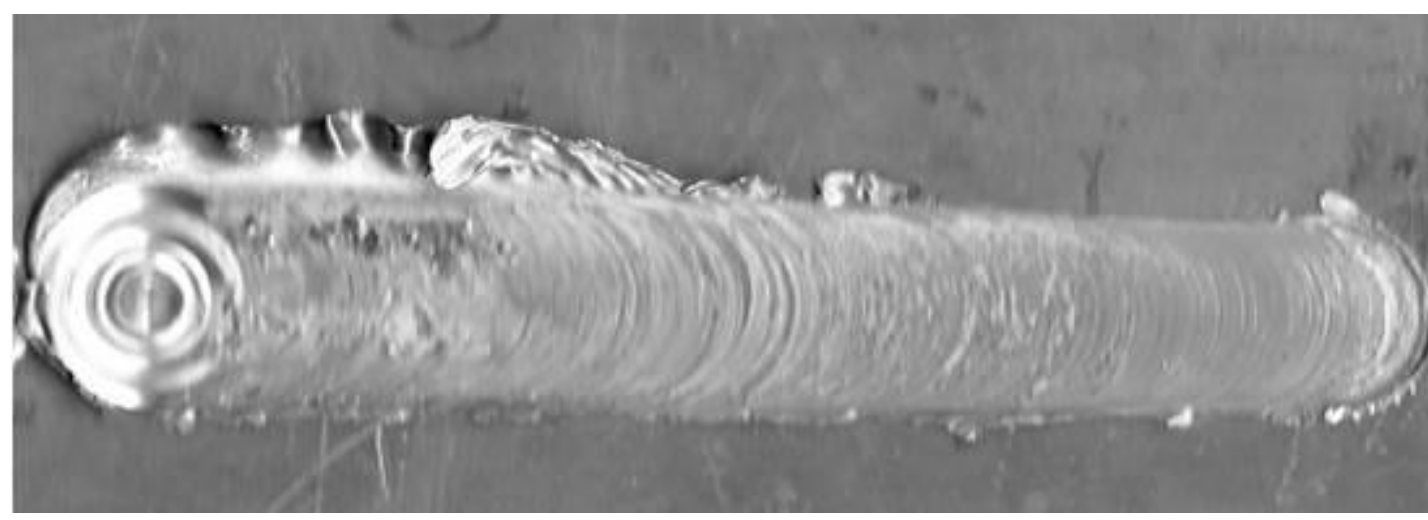

Fig.3 Gray scale image of specimen 1 


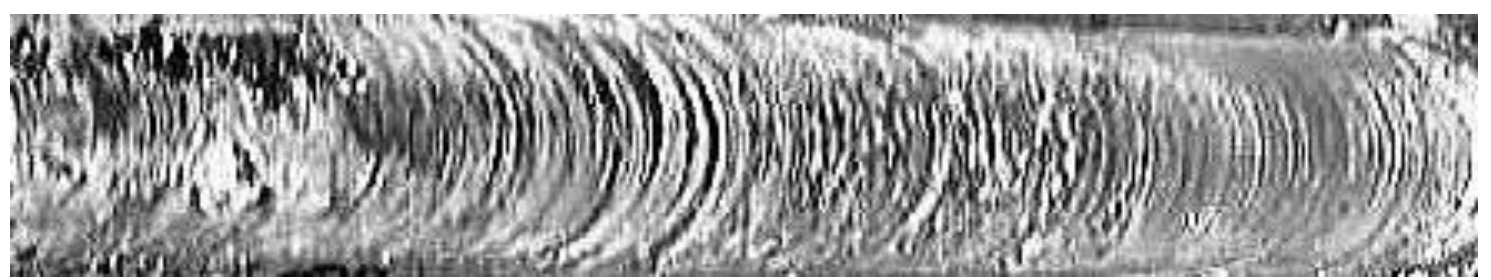

Fig.4 Gray scale, processed weld bead image of Specimen 1

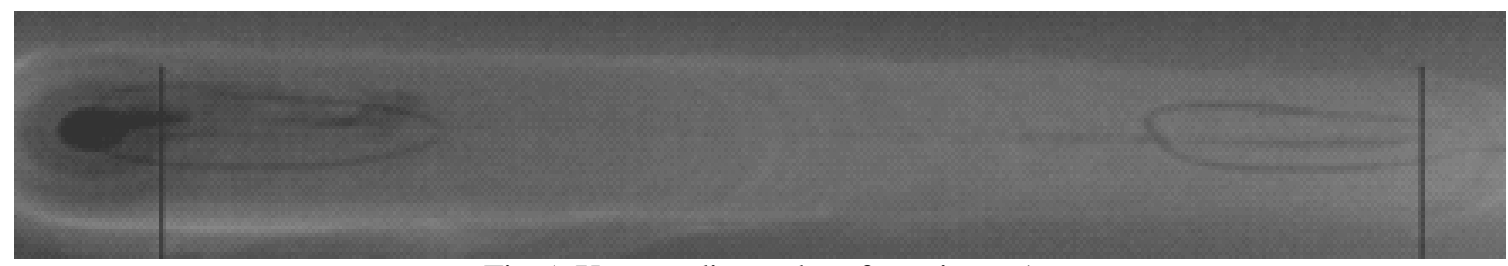

Fig.5: X-ray radiography of specimen 1

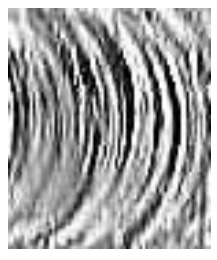

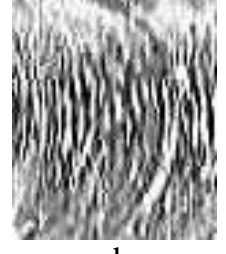

b

Fig.6 Gray scale, processed images of good weld region of specimen 1

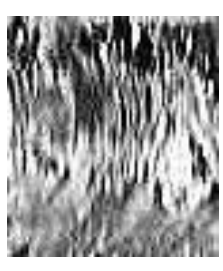

c

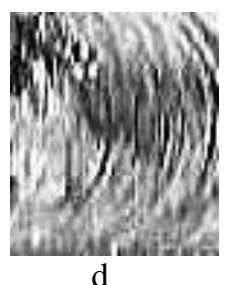

d

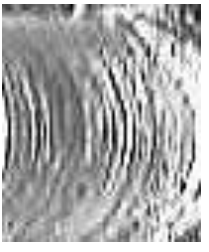

Fig.7 Gray scale, processed images of defect weld region of specimen 1
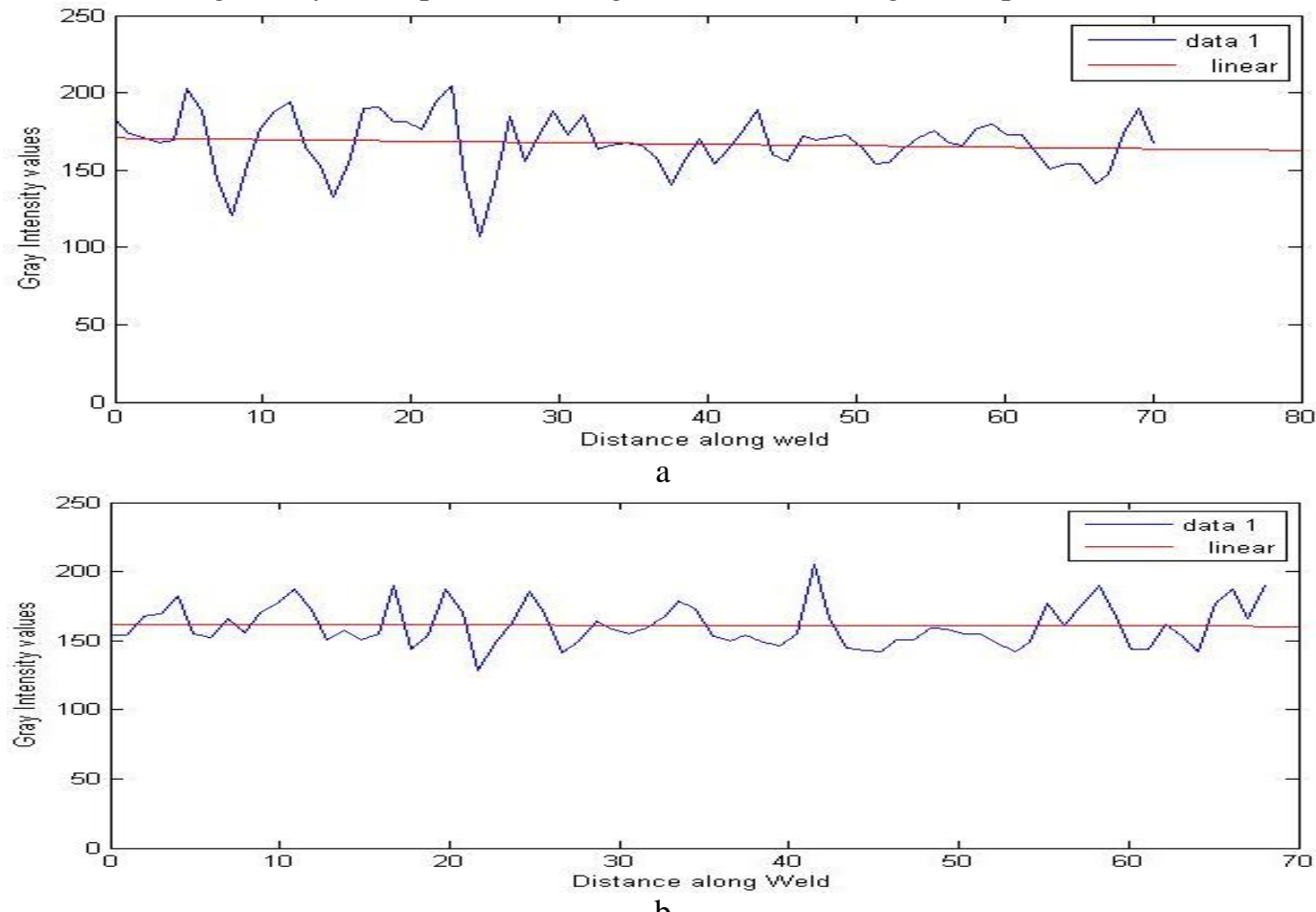

Fig.8 Line profile plot with linear fit of images of good weld region of specimen1 


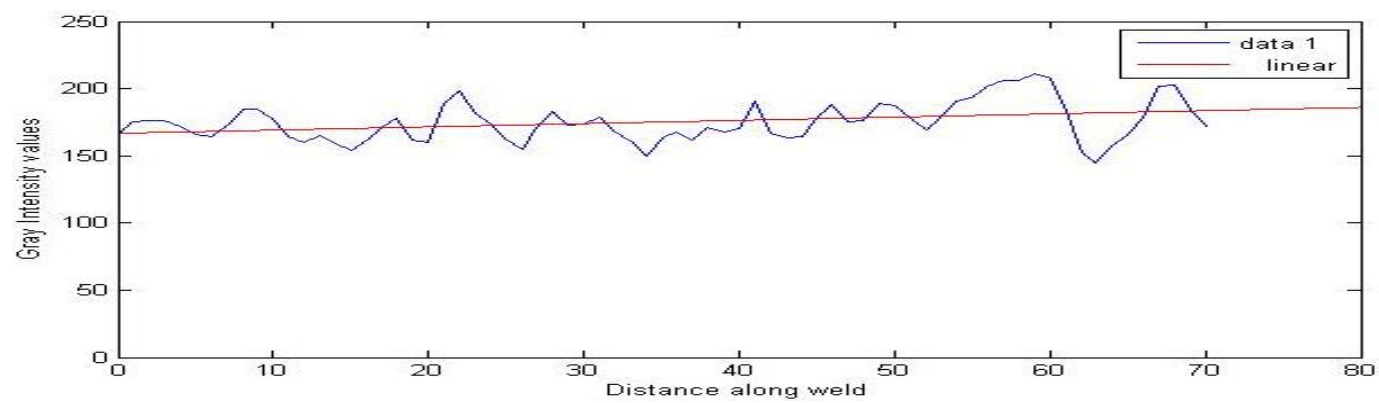

c

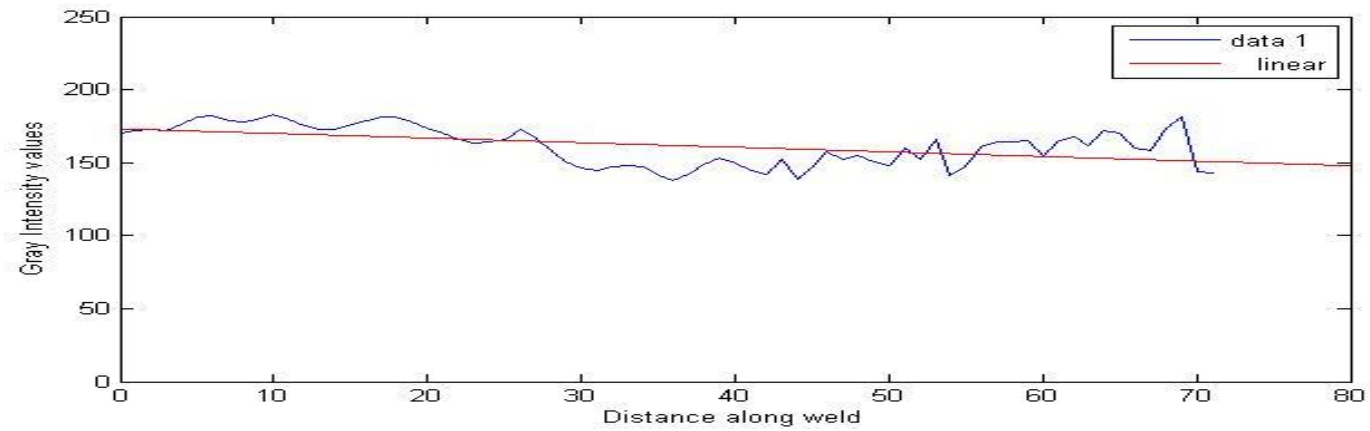

d

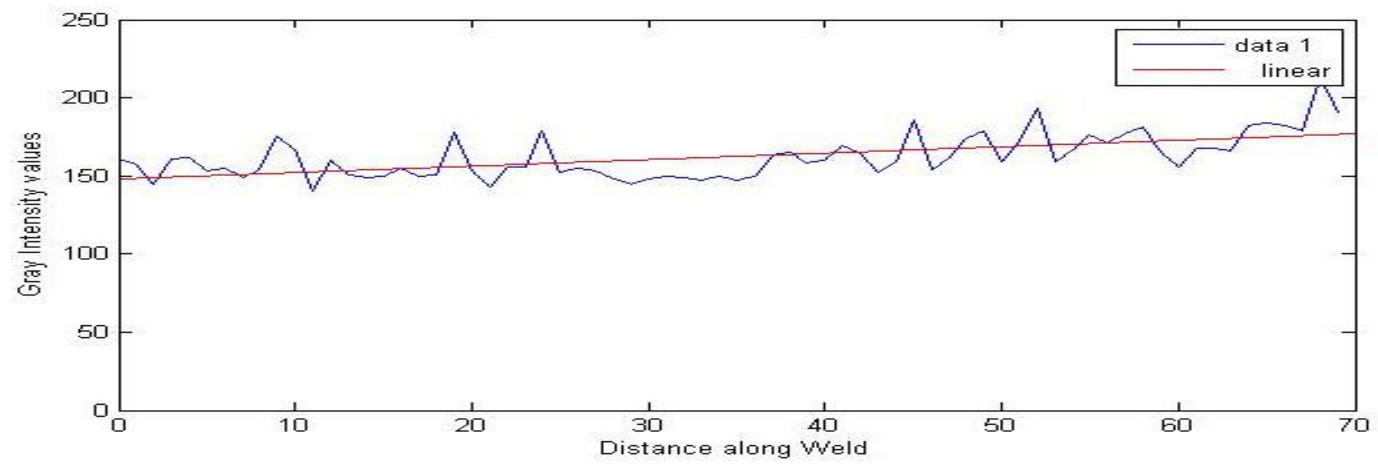

e

Fig.9 Line profile plot with linear fit of images of defect weld region of specimen1

Table 2 Slope of linear fit of line profile plot of specimen 1

\begin{tabular}{|c|c|c|}
\hline $\begin{array}{c}\text { Weld bead } \\
\text { images }\end{array}$ & \multirow{2}{*}{ Weld region } & Slope \\
\hline y & \multirow{2}{*}{ Good } & $7.92^{0}$ \\
\cline { 1 - 1 } $\mathrm{b}$ & & $1^{0}$ \\
\hline $\mathrm{c}$ & \multirow{3}{*}{ Defect } & $17.25^{0}$ \\
\cline { 1 - 1 } $\mathrm{d}$ & $17.25^{0}$ \\
\cline { 1 - 1 } $\mathrm{e}$ & $21.83^{0}$ \\
\hline
\end{tabular}

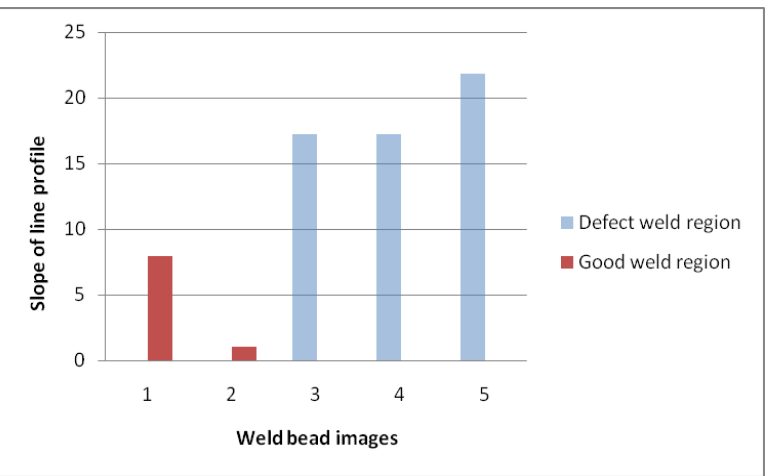

Fig.10 Slope plot of linear fit of line profile plot of specimen 1 

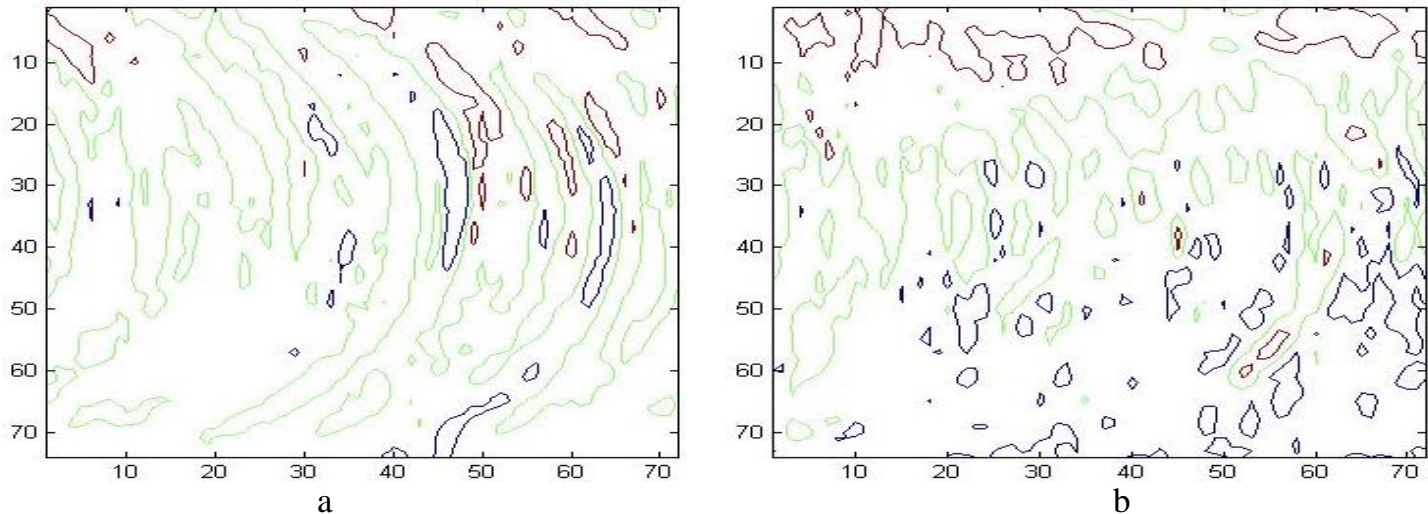

Fig11 Contour plot of images of good weld region of specimen 1
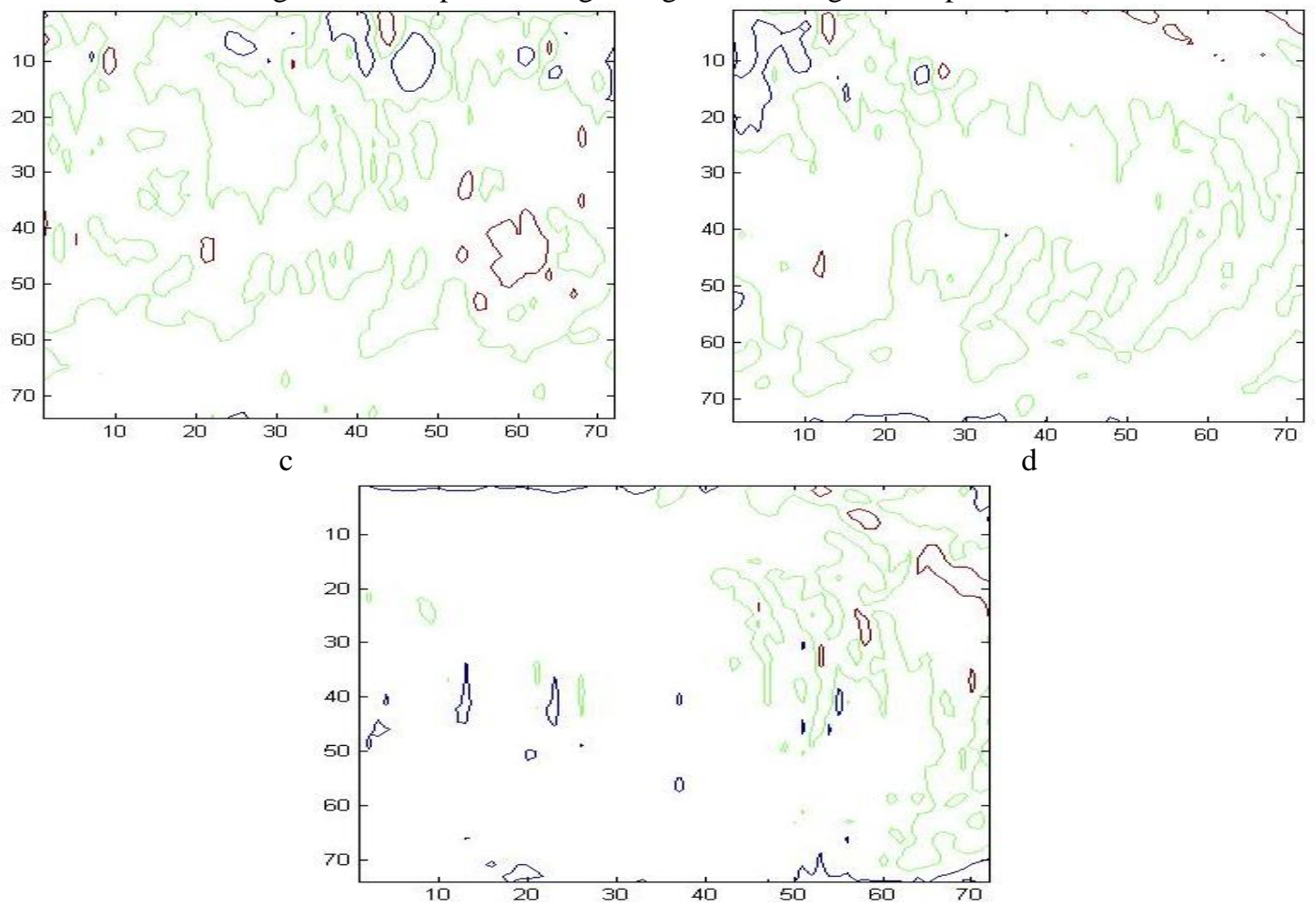

Fig 12 Contour plot of images of defect weld region of specimen 1

profile plots of images of good weld region shows less variation in gray intensity values along weld line than defect weld region. Further, variations in image data is quantified by finding the slope of linear fit of profile plot (TABLE 3). The Fig.20 clearly shows that the slope of good weld region are smaller than that of defect weld region indicating less variation in gray intensity values.

The contour plot of images of good weld region (Fig.21) and defect weld region (Fig.22) of specimen 2 are plotted. The contour plot of good weld region shows consistency in the contouring data. The contour lines are continuous and uniform along weld zone which indicates proper interaction of shoulder during weld formation. The contour plot of defect weld region shows broken and discontinuous contour along weld zone indicating improper interaction of shoulder leading to defect in the weld. 


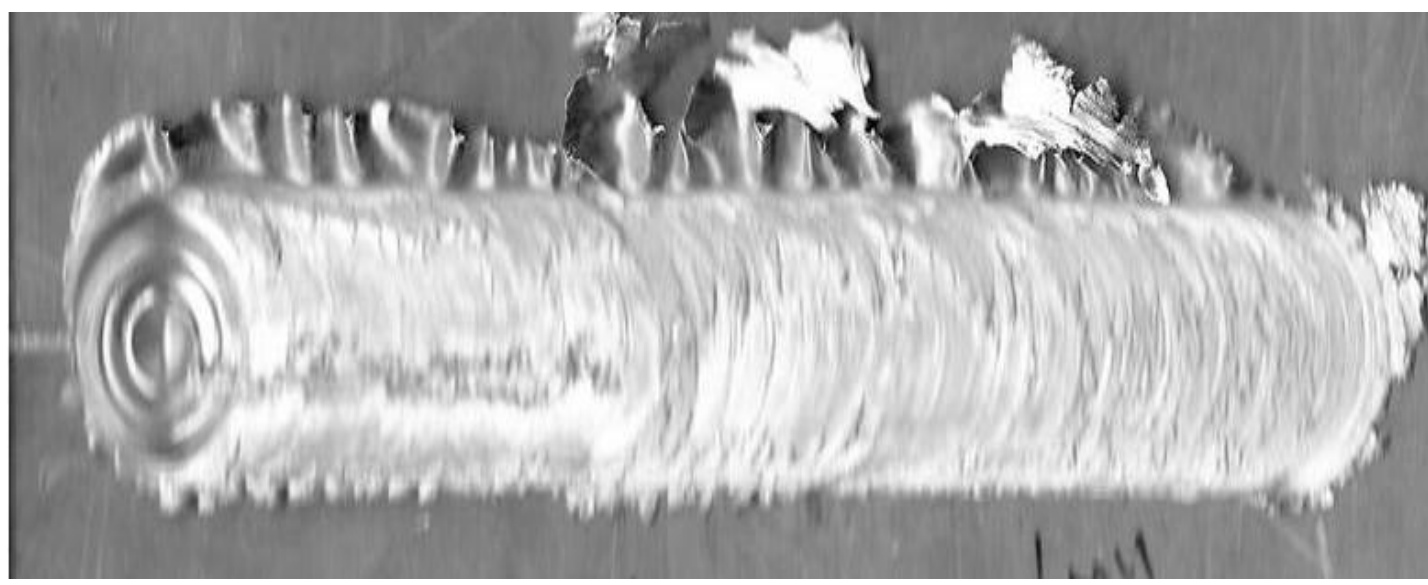

Fig.13 Gray scale image of specimen2

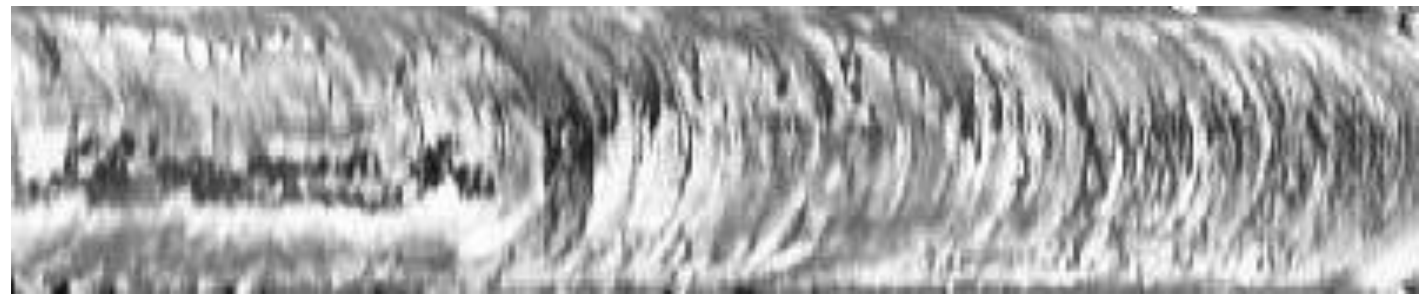

Fig.14 Gray scale, processed weld bead image specimen2

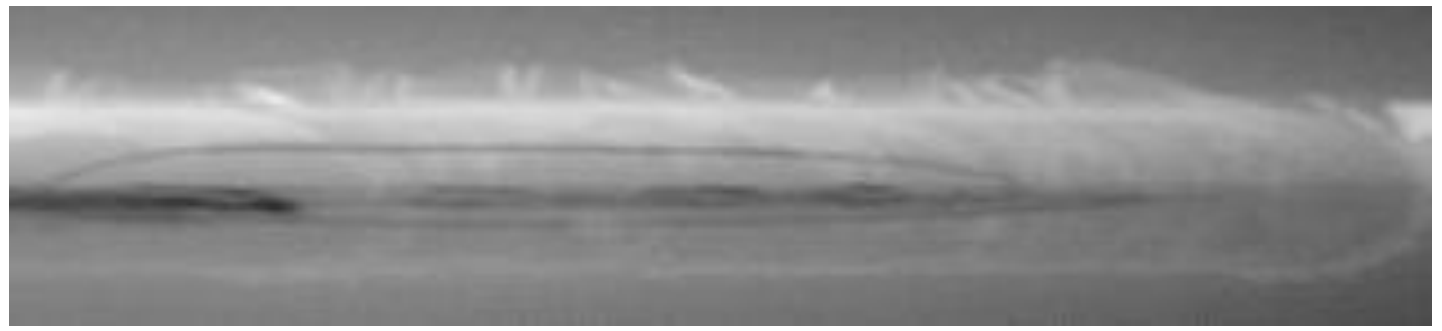

Fig.15 X-ray radiography of specimen 2

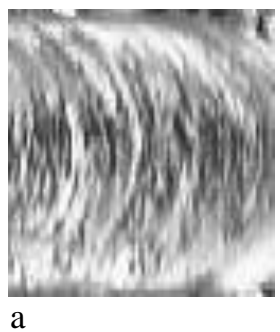

Fig.16 Gray scale, processed image of good weld region of specimen 2

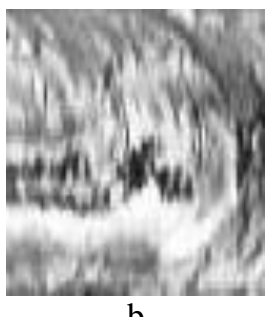

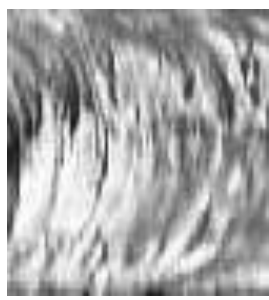

$c$

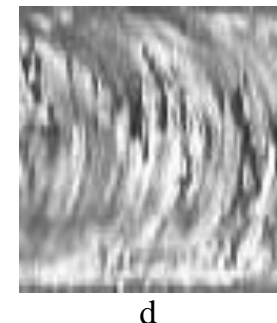

d

Fig. 17 Gray scale, processed images of defect weld region of FSW specimen 2 


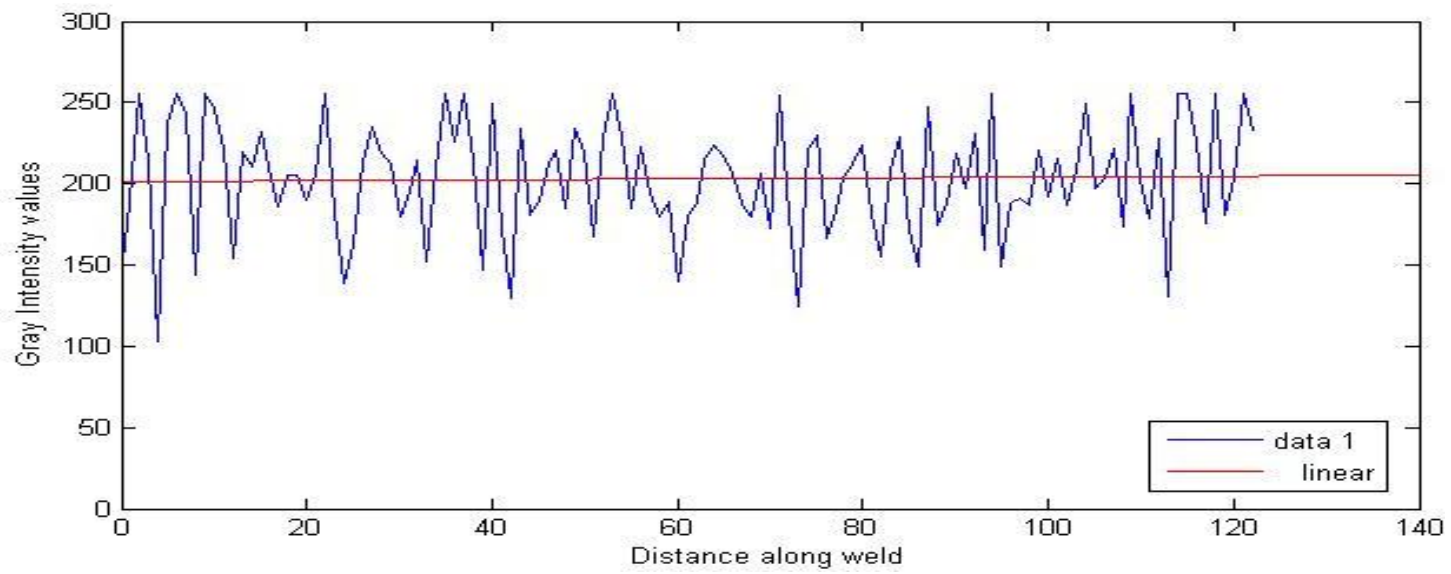

Fig.18 Line profile plot with linear fit of image of good weld region of specimen 2

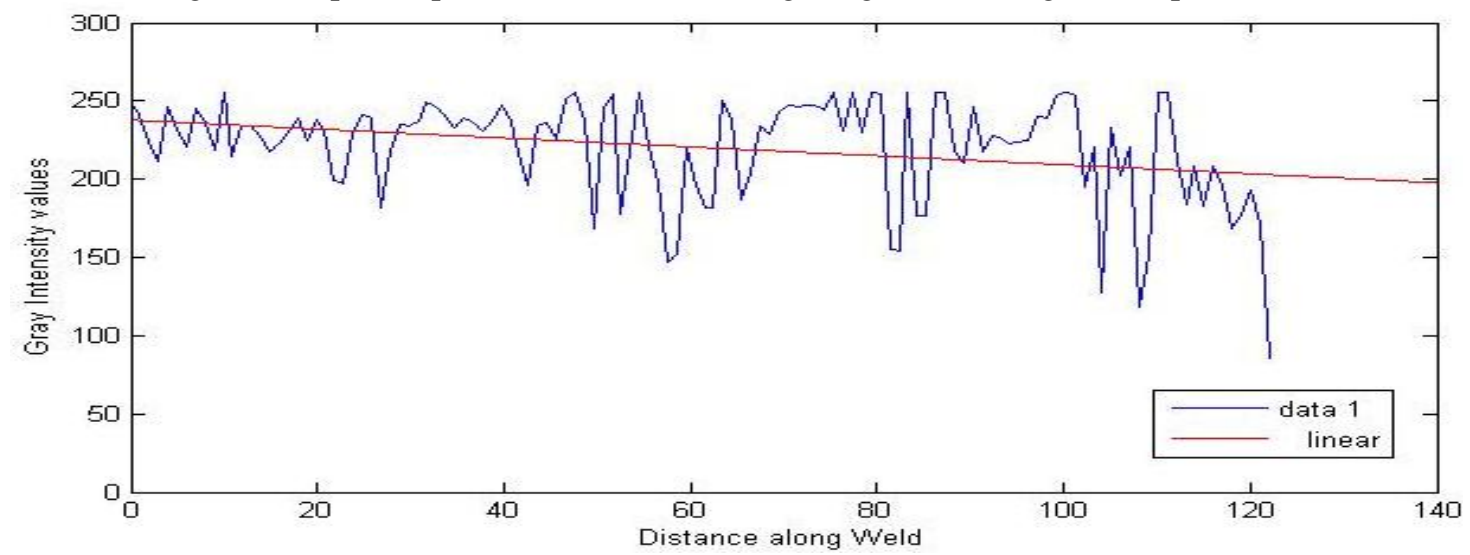

$\mathrm{b}$
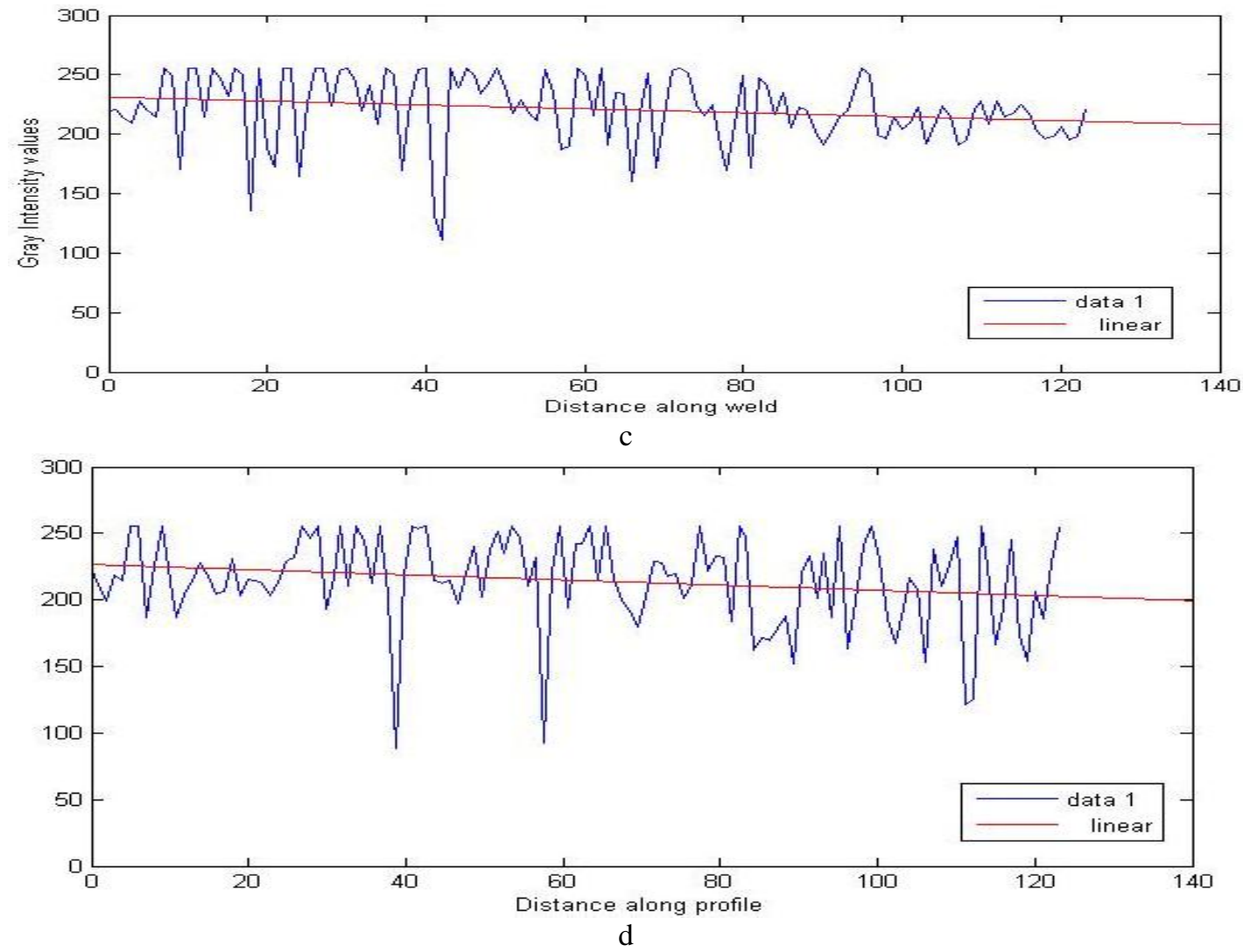

Fig.19 Line profile plot with linear fit of images of defect weld region of specimen 2 
Table 3 Slope of linear fit of line profile plot of specimen2

\begin{tabular}{|c|c|c|}
\hline $\begin{array}{c}\text { Weld bead } \\
\text { images }\end{array}$ & Weld region & Slope \\
\hline $\mathrm{y}$ & Good & $2.84^{0}$ \\
\hline $\mathrm{b}$ & & $17.25^{0}$ \\
\cline { 1 - 1 } $\mathrm{c}$ & \multirow{2}{*}{ Defect } & $11.25^{0}$ \\
\cline { 1 - 1 } $\mathrm{d}$ & & $11.25^{0}$ \\
\hline
\end{tabular}

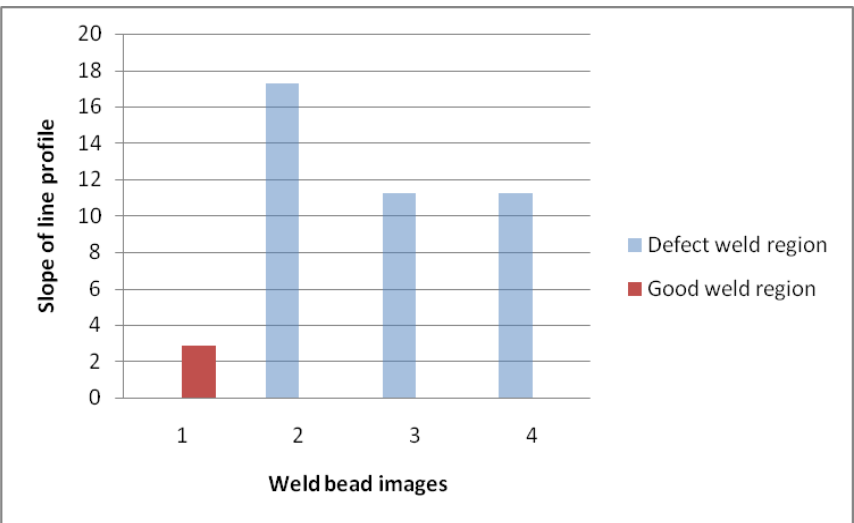

Fig.20 Slope plot of linear fit of line profile plot of specimen2

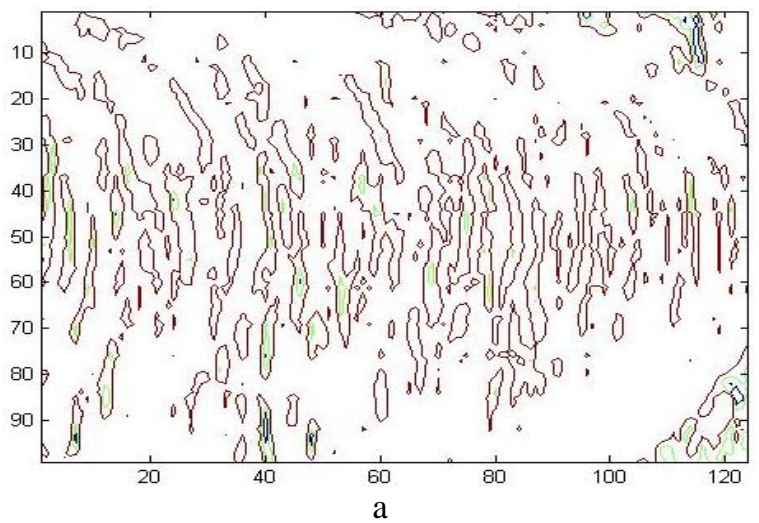

Fig.21 Contour plot of image of good weld region of specimen2
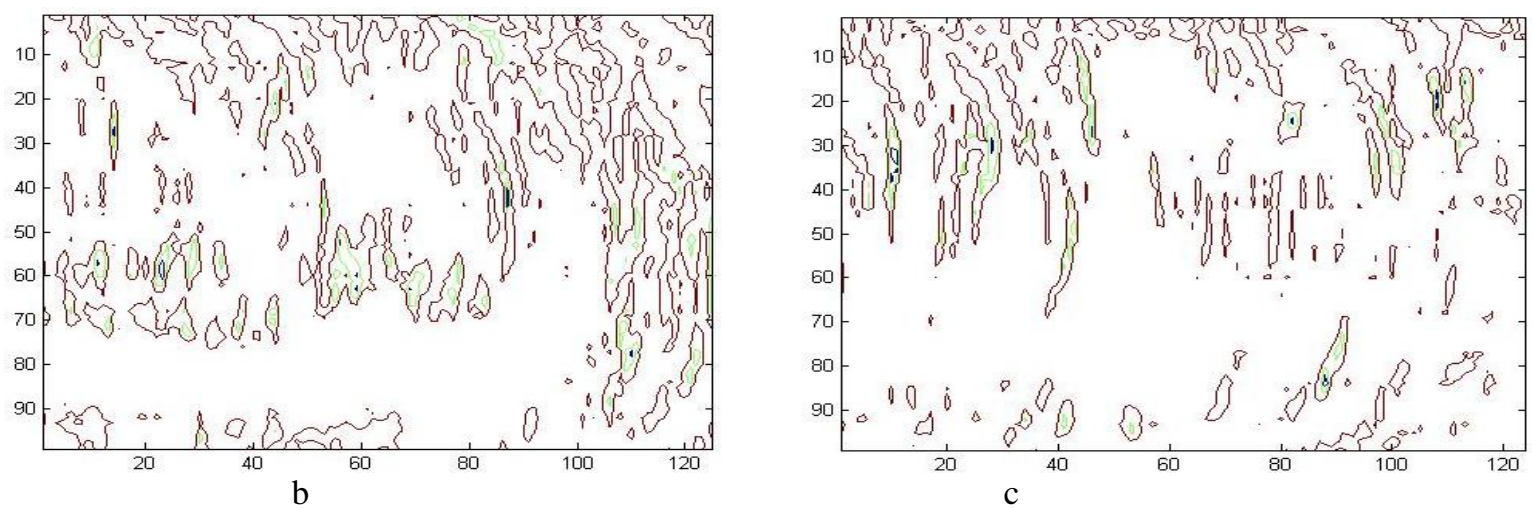


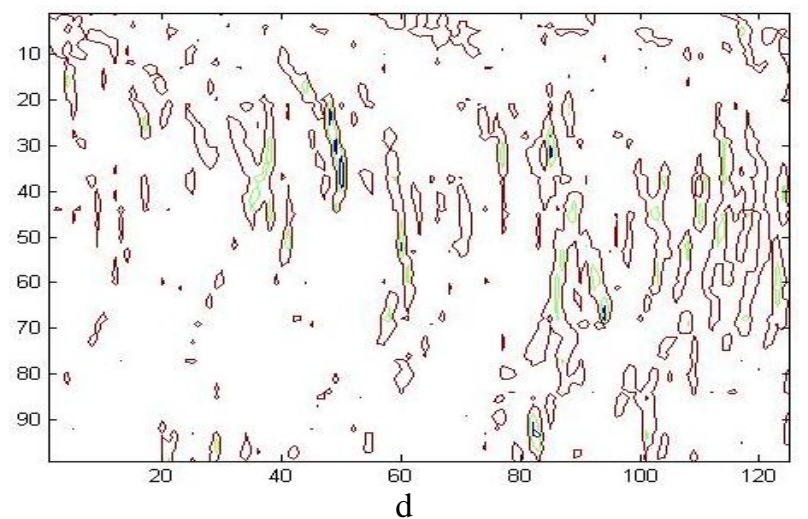

Fig.22 Contour plot of images of defect weld region of specimen2

\section{Conclusion}

In the present study, digital image processing technique is adopted for analysis of weld bead surface which is produced by tool shoulder interaction with underneath base material during FSW. The image parameters of weld bead surface are quantified by computing the slope of line profile plot and generating contour plot of images along weld line, which shows clear variations with respect to good and defect regions of welded specimens. Among line profile plot and contour plot, it has been observed that there is a clear demarcation between good weld and defect weld with respect to line profile plot than contour plot. Further, the methodology followed in the present work may be adopted for automation of the FSW process by means of online monitoring system, which can improve the quality and productivity after standardizing the parameters involved in FSW and Digital Image Correlation.

\section{References}

[1]. W.M. Thomas, E.D. Nicholas, J.C. Needham, M.G. Murch, P.T. Smith, and C.J. Dawes, International Patent No. PCT/GB92/02203, GB Patent No. 9125978.8 (1991), US Patent No. 5,460,317 (1995)

[2]. J.H. Ouyang and R. Kovacevic, Material Flow and Microstructure in the Friction Stir Butt Welds of the Same and Dissimilar Aluminum Alloys, J. Mater. Eng. Perfom., 2002, 11(1), p 51-63

[3]. K. Elangovan, V. Balasubramanian, and S. Babu, Developing an Empirical Relationship to Predict Tensile Strength of Friction Stir Welded AA2219 Aluminum Alloy, Journal of Materials Engineering and Performance (2008) 17:820-830

[4]. A. Scialpi , L.A.C. De Filippis, P. Cavaliere, Influence of shoulder geometry on microstructure and mechanical properties of friction stir welded 6082 aluminium alloy, Materials and Design 28 (2007) 1124-1129

[5]. Dwight A. Burford, Bryan M. Tweedy and Christian A. Widener, Influence of shoulder configuration and geometric features on FSW track properties, 6th International Symposium on Friction Stir Welding Saint-Sauveur, Nr Montréal, Canada, October 10-13, 2006

[6]. S.Muthukumaran and S.K.Mukherjee, Multi-layered metal flow and formation of onion rings in friction stir welds, International Journal of Advanced Manufacturing Technology(2008), 36:68-73.

[7]. K. Kumar and Satish V.Kailas, The role of friction stir welding tool on material flow and weld formation, Materials Science and Engineering A, 485(2008), 367-374.

[8]. K.Kumar and Satish.V.Kailas, On the role of axial load and the effect of interface position on the tensile strength of a friction stir welded aluminium alloy, Materials and Design 29 (2008) 791-797.

[9]. A J Leonard and S A Lockyer "Flaws in Friction Stir welds" $4^{\text {th }}$ International Symposium on Friction Stir Welding, Park City, Utah, USA, 14-16 May 2003.

[10]. Shaowen XU and Xiaomin Deng, A study of texture patterns in friction stir welds, Acta Materialia 56 (2008) 1326-1341.

[11]. S.Muthukumaran, Preetish Sinha, R.Sivakumar and S.K.Mukherjee, "Condition monitoring of first mode of metal transfer in friction stir welding by image processing techniques", International Journal of Advanced Manufacturing Technology(2008), volume 36, pages 484-489. 